\title{
Editorial
}

\section{The challenge of conducting gambling research}

Donald W. Black

\section{Summary}

Responding to the survey of 5580 college students in South India in the study of George et al, the author discusses the universality of addictive gambling and its stereotyped nature. This study, together with work in North America and elsewhere, argues for more research that targets prevalence, risk factors, course, and treatment. The author points out the challenge of conducting research when funding is hard to obtain.

\section{Declaration of interests}

None.

\section{Copyright and usage}

(C) The Royal College of Psychiatrists 2016. This is an open access article distributed under the terms of the Creative Commons Non-Commercial, No Derivatives (CC BY-NC-ND) license.
Donald Black is Professor of Psychiatry and Vice Chair for Education in the Department of Psychiatry at the University of lowa Carver College of Medicine. He has researched pathological gambling and other behavioural addictions for over 20 years. He is an authority on borderline and antisocial personality disorders and authored Bad Boys, Bad Men: Confronting Antisocial Personality Disorder (Sociopathy). His work has been profiled in media worldwide.

Problem gambling has reached a critical stage as evidenced by a study by George et $a^{1}$ showing the prevalence and correlates of problem gambling among 5580 randomly selected college students in South India. The researchers found that 38\% of those who gambled were problem gamblers. Problem gambling in general, and its more severe counterpart pathological gambling, is universal. An inescapable conclusion from the study of George et al is that problem gambling is similar whether it occurs in South India or North America, and presumably other parts of the world.

The study of George et al shows that problem gambling tends to primarily affect men, those with substance misuse who are psychologically distressed, and is associated with suicidality. In North America, among college students gambling often takes the form of sports betting or internet gambling, though in this survey the lottery was the most popular gambling activity. The consequences of problem gambling are universal as well: depression, addiction, domestic violence, and bankruptcy. Beyond the individual, gambling and its consequences have an enormous - and adverse - impact on the economy, pegged at $\$ 54$ billion in the United States. ${ }^{2}$ For problem gambling and pathological gambling to exist, gambling opportunities must be readily available. Even when they are not, internet gambling is available $24 / 7$, except perhaps in countries that restrict internet access.

What happens to people with pathological gambling over time? The Diagnostic and Statistical Manual of Mental Disorders, 5th edition (DSM-5) ${ }^{3}$ promotes the idea that the disorder is chronic and progressive and proceeds through multiple stages. In fact, this may not be true. Our own group (unpublished data) recently showed that pathological gambling age at onset is bimodal with women having a later onset and that disorder intensity diminishes over time, a finding consonant with recent reviews. ${ }^{4}$ People with pathological gambling are not sentenced to a dire outcome, and some improve spontaneously without treatment. These findings prompt another question: can treatment accelerate improvement in pathological gambling? This has never been clear nor has there been any consensus on what constitutes treatment. Treatments include self-exclusion programmes, 12 -step programmes such as Gamblers Anonymous, individual or group psychotherapy emphasising cognitive-behavioural therapy and motivational interviewing, and, at least for a small number of patients, psychotropic medication. ${ }^{5,6}$ While many of these treatments are routinely recommended, and many people appear to benefit from them, they are not widespread other than perhaps Gamblers Anonymous chapters.

Why are there such large knowledge gaps in the pathological gambling literature? While traditional addictions have received intensive study, behavioural addictions including pathological gambling have generally been ignored. ${ }^{2}$ The fact that pathological gambling (now renamed gambling disorder) has been moved to the chapter on addictions in DSM-5 may help reinvigorate research. In the United States, the National Institutes of Health (NIH) has been the traditional funder of research. Unfortunately, the NIH has shown little interest in funding gambling research since a brief surge in funding in the early 2000s. Thus, studies on prevalence, risk factors, course, and treatment are ignored and funding has been limited. On the contrary, Canada provides governmental support for gambling research and sees this as a priority. This has led to a vibrant research environment and diverse projects investigating every relevant aspect of addictive gambling. Perhaps the research of George et $a l^{1}$ will help alert funding agencies that addictive gambling, as a worldwide scourge, merits greater attention.

Donald W. Black, MD, Department of Psychiatry, Carver College of Medicine, University of lowa, 2-126b Medical Education Building, Iowa City, IA 52242, USA. Email: donald.black@uiowa.edu

First received 25 Apr 2016, final revision 31 Aug 2016, accepted 31 Aug 2016

\section{References}

1 George S, Jaisoorya TS, Nair BS, Rani A, Menon PG, Madhavan R, et al. A crosssectional study of problem gambling and its correlates among college students in South India. Br J PSychiatry Open 2016; 2: 199-203.

2 Yau YH, Potenza MN. Gambling disorder and other behavioral addictions: recognition and treatment. Harv Rev Psychiatry 2015; 23: 134-46. 
3 American Psychiatric Association. Diagnostic and Statistical Manual of Mental Disorders (5th edn). APA, 2013.

4 Black DW, Coryell WH, Crowe RR, Shaw M, McCormick B, Allen J. Age at onset of DSM-IV pathological gambling in a non-treatment sample: early- versus later-onset. Compr Psychiatry 2015; 60: 40-6.

5 Petry NM, Blanco C. National gambling experiences in the US: will history repeat itself? Addiction 2013; 108: 1032-7.
6 McIntosh CC, Crino RD, O'Neill K. Treating problem gambling samples with cognitive behavioural therapy and mindfulness-based interventions: a clinical trial. Gambl Stud 4 Apr 2016 (Epub ahead of print).

OPEN 